\title{
Estimated General Equilibrium Models for the Evaluation of Monetary Policy in the US and Europe* $^{*}$
}

\author{
Campbell Leith ${ }^{\dagger}$ \\ Jim Malley \\ University of Glasgow \\ University of Glasgow
}

January 9, 2002

\begin{abstract}
A persistent criticism of general equilibrium models of monetary policy which incorporate nominal inertia in the form of the New Keynesian Phillips Curve (NKPC) is that they fail to capture the extent of inflation inertia in the data. In this paper we derive a general equilibrium model based on optimising behaviour, but which also implies a data consistent NKPC. Specifically our model accounts for nominal inertia in both price and wage setting as well for habits in consumption. Using US and European data from 1970 to 1998 our parameter estimates reveal that (i) there is relatively more inertia in price-setting in Europe; (ii) wage contracts last longer in the US; (iii) the extent of backward-looking behaviour in price and wage setting is statistically significant but small in both the US and Europe; and (iv) significant habits effects are present in European consumption. Finally we simulate the effects of monetary policy and find that while the magnitude of the impact of monetary policy on the endogenous variables in our estimated models are similar to other econometric studies, the dynamic paths for variables display less inertia than is typically found in studies which use output gaps to proxy changes in marginal costs.
\end{abstract}

JEL Codes: E10, E3, E52

${ }^{*}$ We would like to thank Julia Darby and Simon Wren-Lewis for helpful comments on an earlier draft of this paper. We would also like to thank Jordi Galí, Mark Gertler and David López-Salido for providing us with their US and Euro area data. Finally Campbell Leith would like to thank the ESRC (Grant No.L138251050) for financial support in conducting this research.

${ }^{\dagger}$ Corresponding Author: Campbell Leith, Department of Economics, University of Glasgow, Adam Smith Building, Glasgow G12 8RT, UK; (Tel.) ++44(0)141-330-3702; (Fax) ++44-(0)141-330-4940; (E-mail) c.b.leith@socsci.gla.ac.uk; (Web) http://www.gla.ac.uk/economics/leith/. 


\section{Introduction}

Despite the reputation of macroeconomics as a subject plagued by numerous ideological disputes, some authors are now arguing that the field is developing a new consensus (see, for example, Woodford (1999) and Goodfriend and King (1997)). The latter authors have gone as far as dubbing this emerging view, 'The New Neo-Classical Synthesis' (NNCS). Essentially the NNCS extends the optimising behaviour underlying the Real-Business Cycle (RBC) literature to include the frictions considered by New Keynesian Economists in the 1980s (see Mankiw and Romer (1991) for a collection of influential papers). As a result the NNCS can use the insights of RBC theory to explain equilibrium output, while, at the same time, explaining deviations of actual output from equilibrium as a result of stickiness in the adjustment of prices and wages. The NNCS paradigm has been employed in numerous academic studies of monetary policy (see, for example, Rotemberg and Woodford (1997), Clarida et al (1999), Taylor (1999), and Erceg at al (2000)). Moreover the NNCS has come to dominate policy evaluation in central banks throughout the world (see Taylor (1999)) and has even been suggested as the most relevant macroeconomic framework to teach to undergraduate students (see Taylor (2000) and Romer (2000)).

The NNCS can best be understood with reference to a simple benchmark model for the analysis of monetary policy ${ }^{1}$. Firstly, there is an equation relating the output gap, $\widehat{y}_{t}$, to the future deviation of actual from potential output and negatively to the real interest rate,

$$
\widehat{y}_{t}=E_{t} \widehat{y}_{t+1}-\frac{1}{\rho} E_{t} \widehat{r}_{t}
$$

where $1 / \rho$ measures the sensitivity of output to changes in the ex-ante real interest rate, $E_{t} \widehat{r}_{t}$. A relationship of this kind can be derived from the optimal decisions of consumers seeking to maximise their lifetime utility. These consumers may operate as yeoman farmers producing a differentiated product or they may supply their labour to imperfectly competitive firms. Either way it is assumed that the price of these differentiated products cannot be adjusted continuously to clear markets. Instead prices are often assumed to be fixed for a random period of time as in Calvo (1983) and price setters therefore take this into account when setting today's price. This gives rise to the 'New Keynesian' Phillips Curve (NKPC),

$$
\widehat{\pi}_{t}=E_{t} \widehat{\pi}_{t+1}+\alpha \widehat{y}_{t}
$$

which relates current inflation to expected future inflation and the output gap. The model is then closed by the inclusion of a simple monetary policy rule usually, although not always, framed in terms of interest rates rather than monetary aggregates. An influential example is the rule suggested by Taylor (1993),

$$
\widehat{R}_{t}=E_{t} \widehat{\pi}_{t+1}+\frac{1}{2} \widehat{\pi}_{t}+\frac{1}{2} \widehat{y}_{t}
$$

\footnotetext{
${ }^{1}$ Here a 'hatted' variable denotes percentage deviations from steady-state to make it clear that we are focusing on the New Keynesian features of the synthesis which make it a suitable framework for the evaluation of monetary policy.
} 
which says that monetary policy operates to stabilise short-run deviations of inflation from target and output from potential. The microfoundations of the NNCS also enables welfare measures to be constructed from the utility functions of the economic agents populating these models (see, for example, Woodford (1999)).

However, despite the popularity of models of this form in designing and evaluating monetary policy, they have been criticised on empirical grounds (see, for example, Mankiw and Reis (2001)). One of the main criticisms of these models is the apparent lack of empirical support for the NKPC. For example, Gali and Gertler (2000) report that estimating a NKPC in the form of (2) for the US and Europe tends to produce a wrongly signed coefficient on excess demand. Accordingly when Fuhrer and Moore (1995) estimate a hybrid model,

$$
\widehat{\pi}_{t}=b E_{t} \widehat{\pi}_{t+1}+(1-b) \widehat{\pi}_{t-1}+\alpha \widehat{y}_{t}
$$

they find that the coefficient on lagged inflation is both large and statistically significant $^{2}$. This is taken as evidence that the NKPC given by (2) is misspecified as it cannot account for the strong degree of inflation inertia that regressions based on (4) suggest.

Galí and Gertler (1999) and Sbordone (2001) have challenged this view in their estimates of hybrid NKPC curves for the US, while Galí et al (2001) have done the same for Europe. They point out that deriving the Phillips curve from profit-maximising behaviour reveals that implicitly the output gap term is proxying changes in producers' marginal costs. They show that it is only in the absence of labour market frictions (which can be either real or nominal) that the output gap, $\widehat{y}_{t}$, will actually be proportional to marginal costs. When they replace the output gap with a measure of demeaned marginal costs, defined as the ratio of the real wage to the marginal product of labour

$$
M C_{t}=\frac{\left(W_{t} / P_{t}\right)}{(1 / \phi)\left(Y_{t} / N_{t}\right)}
$$

where $\phi$ comes from a Cobb-Douglas production function defined as, $Y_{t}=N_{t}^{\frac{1}{\phi}}$, they find that the statistical problems associated with the NKPC are overcome ${ }^{3}$. The extent to which price setting behaviour is backward looking, although statistically significant, is quantitatively small and they conclude that "the [NKPC] fits the data very well" in both the US and Europe (see Galí et al (2001)).

While these papers offer support for the NKPC, it is not clear how researchers wishing to utilise models such as the benchmark model outlined above

\footnotetext{
${ }^{2}$ Rewriting the NKPC (2) as $\Delta \widehat{\pi}_{t+1}=-\alpha \widehat{y}_{t}$ reveals that the coefficient on the output gap, when it is regressed on the changes in inflation, should be negative. However, as noted above, it is typically found to be weakly positive. The converse of this is that regressions of Phillips curves assuming adaptive adaptive expectations $\Delta \widehat{\pi}_{t}=\alpha \widehat{y}_{t}$ produce significantly positive coefficients on the output gap. Therefore, hybrid Phillips curves, which are essentially a weighted average of the backward-looking Phillips curves and the NKPC, suggest a significant role for backward-looking behaviour in price setting.

${ }^{3}$ Gagnon and Khan (2001) have analysed the robustness of these results across different specifications of utility and production functions for Canada, the US and Europe.
} 
should proceed. As it stands the benchmark model is mis-specified since the assumption that the output gap is a good proxy for movements in marginal costs is incorrect and the co-movements of variables predicted by this model are therefore likely to be unrealistic. However, the extensions to the basic model required to capture the link between the output gap and marginal costs have not yet been formalised. The current paper attempts to bridge this gap by deriving a general equilibrium model which allows for both real frictions (as proxied by consumption-habit effects in labour supply) and nominal frictions in the labour market as a source of the disparity between the output gap and marginal costs.

Specifically, in Section 2 we derive a model where consumers allocate their consumption optimally across time allowing for the fact that the utility they derive from current consumption and leisure depends upon their levels of consumption in the past. Consumers also supply their labour to imperfectly competitive firms. They are the monopolistic suppliers of that labour, and we allow for the possibility that wages can only be renegotiated at random intervals. We further assume that some workers attempt to maximise their utility over the expected life of the wage contract, while others follow a simple backward-looking rule of thumb in resetting wages. This allows us to identify the extent of forward and backward-looking behaviour in wage setting. The imperfectly competitive firms hiring this labour are also only able to adjust their prices at random intervals. Some firms will reset prices by selecting a price which maximises the expected discounted value of firm profits, while others will implement a backward-looking rule of thumb which will lead them to select the profit maximising price in the long-run.

In Section 3, we then estimate this model within a systems-framework using time-series data for both the US and Europe to obtain estimates of the structural parameters of the model. While it is interesting to examine each of these economies individually, it is also insightful to be able to make a comparison of the monetary transmission mechanism in both economies using a common framework. This will, for example, help us assess the extent to which the very different labour market institutions in Europe and the US manifest themselves in differing degrees of nominal inertia and real inertia. Our econometric work further allows us to obtain estimates of the degree of nominal inertia in both wages and prices in the two economies, along with the extent to which economic agents using backward-looking rules-of-thumb, as opposed to intertemporal optimisation, in setting wages and prices. We also attempt to quantify the responsiveness of output to interest rates, by estimating the intertemporal elasticity of substitution. Finally, our econometric work provides an estimate of our consumers' rate of time preference, and the extent to which their past levels of consumption affect the utility they derive from current consumption and leisure activities.

Other papers which have attempted to estimate general equilibrium models for the evaluation of monetary policy include Rotemberg and Woodford (1997), who derive parameter estimates for the benchmark model outlined above by matching the implied impulse responses of this model to the impulse responses of an estimated VAR model of the US economy. A similar approach is followed 
in Amato and Laubauch (2001) and in Christiano et al (2001), again using data from the US. In the former the model includes stickiness in wages, as well as prices. The latter allows for habits in consumption and some backward looking behaviour in price and wage setting. However, by adopting a logarithmic specification for utility Christiano et al (op. cit.) essentially impose the size of the response of output to interest rates, which is an effect we prefer to estimate in constructing a model for policy analysis. Fuhrer (2000) estimates consumption functions for the US allowing for habits effects and argues that, in combination with the hybrid Phillips curve estimates in Fuhrer and Moore (1995), this would generate a monetary policy model which accurately describes the hump-shaped responses of inflation and output to monetary policy shocks. However, the policy model employed in their paper implicitly ignores the cross-equation restrictions that deriving the model from microfoundations would imply. McCallum and Nelson (1998) follow a slightly different approach by directly estimating structural parameters using an instrumental variables estimator on US data. The model they derive is essentially the same as the benchmark model outlined above, although they allow for price setting to follow a p-bar model as well as the usual Calvo-formulation.

The plan of the rest of the paper is as follows. Section 2 derives the general equilibrium model. Section 3 then discusses the estimation strategy, results and simulates the output, wage-inflation and price-inflation responses to a one-point one-year rise in the nominal interest rate. Section 4 concludes.

\section{The Model}

In this Section, our aim is to formulate a simple model for policy analysis in the spirit of the benchmark NNCS model discussed in the introduction but which is also data-consistent. Since there is clear evidence that the output gap is a poor indicator of marginal costs (see, for example, Galí and Gertler (1999) and Galí et al (2001)), we extend the benchmark monetary policy model outlined in the Introduction in three directions. Firstly, we consider the possibility that there is nominal inertia in wage setting as well as price setting. Secondly, we allow some price and wage-setters to set prices and wages based on full-optimisation of their intertemporal objectives, while others follow simple rules-of-thumb based on recent observable data. Finally, we introduce the possibility that consumers' consumption and labour supply decisions are intertemporally linked through habits effects in consumption. By allowing for nominal wage inertia and habits effects in consumption/labour supply, we allow for the possibility that the output gap is not proportional to marginal costs. 


\subsection{Consumer Behaviour}

Consumers are assumed to maximise utility over consumption and leisure according to the following objective function,

$$
\operatorname{Max} E_{t}\left[\sum_{s=0}^{\infty} \beta^{s}\left(u\left(c_{t+s}^{i}, h_{t+s}^{i}, \varepsilon_{t+s}\right)+v\left(1-N_{t+s}^{i}, \zeta_{t+s}\right)\right) .\right.
$$

The first felicity represents consumer $i$ 's utility from consumption of a CES basket of consumption goods, $c_{t}^{i}$, defined as,

$$
c_{t}^{i}=\left[\int_{0}^{1} c_{t}^{i}(z)^{\frac{\theta_{p}-1}{\theta_{p}}} d z\right]^{\frac{\theta_{p}}{\theta_{p}-1}}
$$

given the stock of consumption habits, $h_{t}^{i}$, where $\theta_{p}>1$. As $\theta_{p} \rightarrow \infty$, the product market tends towards a state of perfect competition. The second felicity reflects the utility derived from leisure, which is the residual of the individual's time endowment (which has a normalised value of 1) after supplying their labour services to imperfectly competitive firms. Workers are assumed to be the monopolistically competitive suppliers of their labour services, $N_{t}^{i}$. The production function of firms hiring this labour is of the form,

$$
y_{t}(z)=e^{\mu_{t}} \frac{1}{\phi}\left(N_{t}(z)\right)^{\frac{1}{\phi}} \bar{K}(z)^{\sigma}
$$

where $N(z)_{t}$ represents a CES aggregate of all the differentiated labour services provided by households employed by firm $z$,

$$
N_{t}(z)=\left[\int_{0}^{1} N_{t}^{i}(z)^{\frac{\theta_{w}-1}{\theta_{w}}} d i\right]^{\frac{\theta_{w}}{\theta_{w}-1}}
$$

Where, $\theta_{w}>1, \mu_{t}$, is a productivity shock hitting all firms, and $\bar{K}(z)$ is the stock of capital employed by firm $z$, which we assume to be fixed and, for simplicity, is normalised to $1 .{ }^{4}$

The underlying utility function is also subject to consumption taste shocks, $\varepsilon_{t}$, and labour supply taste shocks, $\zeta_{t}$ which, ceteris paribus, affect the marginal utility derived from the consumption basket and leisure, respectively. These taste shocks are common to all consumers. The individual's stock of habits are set equal to their level of consumption in the previous period so that,

$$
h_{t+1}^{i}=c_{t}^{i}
$$

\footnotetext{
${ }^{4}$ The simplifying assumption that the capital stock is fixed is a reasonable one, in the context of the present study, for several reasons (see Amato and Laubauch (2001) for a discussion). In particular, since we are focusing attention on the short-run business cycle properties of a model with sticky prices, the capital stock may reasonably be held to be constant given this time frame. Additionally, Woodford (2000) shows that the inclusion of adjustable firm-specific capital in sticky-price models does not significantly affect the response of output, inflation and marginal costs to monetary policy shocks relative to the case where capital is assumed fixed.
} 
Since each household is the monopolistic supplier of its own differentiated labour services it can choose to set the price of these services. We assume that in each period a proportion, $\left(1-\alpha_{w}\right)$, of households are able to set a new wage. Of these households a proportion, $\left(1-\omega_{w}\right)$, set the new wage by seeking to maximise the discounted value of utility, while the remainder follow a simple rule of thumb. This wage setting behaviour will be described in detail below. However, for the moment it is important to note that this means that otherwise identical households could suffer from idiosyncratic shocks to their income due to the random ability to set wages. Therefore, to make our problem tractable, we follow Erceg et al (2000) in assuming that full financial markets exist, and households can buy state-contingent claims which allow them to protect their consumption from the idiosyncratic shocks associated with staggered wage setting. As a result of these state-contingent claims, and the fact that consumers' preferences and initial holdings of financial wealth are identical, it will be the case that all consumers implement identical consumption plans.

The consumer's flow budget constraint, in real terms, is described by,

$$
\delta_{t, t+1} a_{t+1}^{i}=a_{t}^{i}-c_{t}^{i}+w_{t}^{i} N_{t}^{i}+\Pi_{t}-\tau_{t}
$$

where $\delta_{t, t+1}$ is the stochastic discount factor that gives the current value of real income at date $t+1$ in any given state at time $t$. Accordingly the interest rate on a risk-free real bond must satisfy,

$$
r_{t}=E_{t}\left[\delta_{t, t+1}\right]^{-1} .
$$

$a_{t}^{i}$ is real financial wealth held in the form of state-contingent claims which compensate for income uncertainty due to staggered wage setting, $w_{t}^{i} N_{t}^{i}$ represents the consumer's income from supplying labour services and $\Pi_{t}$ is the consumer's share of the profits from all the imperfectly competitive firms in the economy ${ }^{5}$. Consumers also pay real lump-sum taxation of $\tau_{t}$, which funds government spending of $g_{t}{ }^{6}$.

Utilising the transition equations for financial wealth and the stock of habits, we can formulate the Bellman equation as an unconstrained optimisation in $c_{t}^{i}$,

$$
\begin{aligned}
& V_{t}\left(a_{t}^{i}, h_{t}^{i}, \varepsilon_{t}, \zeta_{t}\right)=\max _{c_{t}^{i}} u\left(c_{t}^{i}, h_{t}^{i}, \varepsilon_{t}\right) \\
& \quad+\beta E_{t} V_{t+1}\left(\delta_{t, t+1}^{-1}\left(a_{t}^{i}-c_{t}^{i}+w_{t}^{i} N_{t}^{i}+\Pi_{t}-\tau_{t}\right), c_{t}^{i}, \varepsilon_{t+1}, \zeta_{t+1}\right) .
\end{aligned}
$$

The first order conditions for this optimisation are, firstly, for consumption,

$$
\begin{aligned}
0=u_{c}\left(c_{t}^{i}, h_{t}^{i}, \varepsilon_{t}\right)-\beta E_{t} \delta_{t, t+1}^{-1} V_{t+1}^{a}\left(a_{t+1}^{i},\right. & \left.h_{t+1}^{i}, \varepsilon_{t+1}, \zeta_{t+1}\right) \\
& +\beta E_{t} V_{t+1}^{h}\left(a_{t+1}^{i}, h_{t+1}^{i}, \varepsilon_{t+1}, \zeta_{t+1}\right)
\end{aligned}
$$

\footnotetext{
${ }^{5}$ In other words, we assume that consumer's hold a well diversified portfolio of all the firms in the economy, allowing them to eliminate the risks due to staggered price setting.

${ }^{6}$ For simplicity we assume that the government's budget constraint is balanced in each period, and that the level of government spending is constant at its steady-state level $\bar{g}$.
} 
while we have the following conditions for the state variables,

$$
\begin{gathered}
V_{t}^{a}\left(a_{t}^{i}, h_{t}^{i}, \varepsilon_{t}, \zeta_{t}\right)=\beta E_{t} r_{t} V_{t+1}^{a}\left(a_{t+1}^{i}, h_{t+1}^{i}, \varepsilon_{t+1}, \zeta_{t+1}\right) \\
V_{t}^{h}\left(a_{t}^{i}, h_{t}^{i}, \varepsilon_{t}, \zeta_{t}\right)=u_{h}\left(c_{t}^{i}, h_{t}^{i}, \varepsilon_{t}\right) .
\end{gathered}
$$

If we substitute equations (15) and (16) into the first order condition for consumption we can rewrite this as,

$$
0=u_{c}\left(c_{t}^{i}, h_{t}^{i}, \varepsilon_{t}\right)-E_{t} V_{t}^{a}\left(a_{t}^{i}, h_{t}^{i}, \varepsilon_{t}, \zeta_{t}\right)+\beta E_{t} u_{h}\left(a_{t+1}^{i}, h_{t+1}^{i}, \varepsilon_{t+1}, \zeta_{t+1}\right) .
$$

Leading this equation one period, multiplying by $\delta_{t, t+1}^{-1}$, applying the law of iterated expectations and substituting into equation (14) yields,

$$
\begin{aligned}
& u_{c}\left(c_{t}^{i}, h_{t}^{i}, \varepsilon_{t}\right)+\beta E_{t} u_{h}\left(c_{t+1}^{i}, h_{t+1}^{i}, \varepsilon_{t+1}\right) \\
&=\beta\left[E_{t} \delta_{t, t+1}^{-1} u_{c}\left(c_{t+1}^{i}, h_{t+1}^{i}, \varepsilon_{t+1}\right)\right. \\
&\left.\quad+\beta E_{t} \delta_{t, t+1}^{-1} u_{h}\left(c_{t+2}^{i}, h_{t+2}^{i}, \varepsilon_{t+2}\right)\right]
\end{aligned}
$$

This is the consumer's Euler equation for consumption in the presence of habits and uncertainty. In general, this equation is unsolveable for general forms of uncertainty. Therefore we will adopt specific functional forms for the utility function $^{7}$, specify the sources of uncertainty and linearise the model around its steady-state. The specific functional form we adopt for utility from consumption is as follows,

$$
u\left(c_{t}^{i}, h_{t}^{i}, \varepsilon_{t}\right)=\frac{e^{\varepsilon_{t}}\left(c_{t}^{i} /\left(h_{t}^{i}\right)^{\nu}\right)^{1-\rho}}{1-\rho} .
$$

This element of the utility function is the same as that considered in Carroll (2001), who also provides a discussion of its properties. We assume, for simplicity, that consumers know of the value of the common taste shocks shocks hitting the economy in period $t$, before they make their consumption and wage setting decisions. Since our assumptions imply that consumers implement idential consumption plans, we can substitute for the marginal utilities of consumption and habits in equation (18) and aggregate across consumers to obtain the aggregate consumption Euler equation in the presence of habits,

$$
\begin{aligned}
& e^{\varepsilon_{t}}\left(\frac{c_{t}}{h_{t}^{v}}\right)^{-\rho} \frac{1}{h_{t}^{v}}-v \beta E_{t}\left[e^{\varepsilon_{t+1}}\left(\frac{c_{t+1}}{h_{t+1}^{v}}\right)^{-\rho} \frac{c_{t+1}}{h_{t+1}^{1+v}}\right] \\
& =\beta\left[E_{t} \delta_{t, t+1}^{-1} e^{\varepsilon_{t+1}}\left(\frac{c_{t+1}}{h_{t+1}^{v}}\right)^{-\rho} \frac{1}{h_{t+1}^{v}}-v \beta E_{t}\left[\delta_{t, t+1}^{-1} e^{\varepsilon_{t+1}}\left(\frac{c_{t+2}}{h_{t+2}^{v}}\right)^{-\rho} \frac{c_{t+2}}{h_{t+2}^{1+v}}\right]\right] .
\end{aligned}
$$

\footnotetext{
${ }^{7}$ As these forms are commonly adopted in the literature this will also allow us to compare our estimates with values adopted either by assumption, calibration or estimation in other studies.
} 
Noting that $y_{t}=c_{t}+g_{t}$ and assuming that government spending is always equal to its steady-state level, allows us to log-linearise this expression as,

$$
\widehat{y}_{t}=-\frac{(1-v \beta)}{\lambda_{c}} \frac{\bar{c}}{\bar{y}} \widehat{r}_{t}+\frac{v(\rho-1)}{\lambda_{c}} \widehat{y}_{t-1}+\frac{\varphi_{c}}{\lambda_{c}} E_{t} \widehat{y}_{t+1}-\frac{v \beta(\rho-1)}{\lambda_{c}} E_{t} \widehat{y}_{t+2}+\frac{\varepsilon_{t}}{\lambda_{c}}
$$

where $\lambda_{c}=\rho+v \rho-v+v^{2} \beta \rho-v \beta-v^{2} \beta, \varphi_{c}=-2 v \beta+v \beta \rho+\rho+v^{2} \beta \rho-v^{2} \beta$, and a 'hatted' variable denotes percentage deviation from a steady-state which, in turn, is denoted by 'barred' variables. The presence of habits mean that current consumption not only depends upon the expectation of future consumption it also depends upon past consumption. There are also real interest rate effects and effects from the consumption taste shock $\varepsilon_{t}$. Setting $\nu=0$, would remove the impact of habits, such that this equation would reduce to the standard Euler equation for consumption.

\subsection{Wage Setting}

We now need to consider the wage-setting behaviour on the part of households. In each period a proportion, $\left(1-\alpha_{w}\right)$, of households are able to set a new wage. It is assumed that of these households a proportion, $\left(1-\omega_{w}\right)$, set the new price by seeking to maximise the discounted value of utility, while the remainder follow a simple rule of thumb. The expected utility gained from a household charging wage $W_{t}^{i}$ in period $t$ is given by the following expression

$E_{t} \sum_{s=0}^{\infty}\left(\alpha_{w} \beta\right)^{s}\left[\begin{array}{c}\left\{\frac{W_{t}^{i}}{P_{t+s}} N_{t+s}^{i}\left(u_{c}\left(c_{t+s}, h_{t+s}, \varepsilon_{t}\right)+\beta E_{t} u_{h}\left(c_{t+s+1}, h_{t+s+1}, \varepsilon_{t+s+1}\right)\right)\right\} \\ +v\left(N_{t+s}^{i}, \zeta_{t+s}\right)\end{array}\right]$.

where the first term in curly brackets represents the real income generated by supplying the $N_{t+s}^{i}$ units of labour demanded by firms at wage, $W_{t}^{i}$, multiplied by the marginal utility of that income in period $t+s$. While the second term in square brackets reflects the utility of leisure which is decreasing in the supply of labour. These per period utilities are discounted using a per-period discount factor, $\alpha_{w} \beta$, which reflects the household's rate of time preference and the probability that the wage $W_{t}^{i}$ will still remain in place in the next period. In order to make this problem tractable we need to substitute the demand curve facing wage-setters, the marginal utility of consumption and the utility of leisure into this objective function.

Maximising the index of labour services (9) for a given level of wage payments and integrating across firms gives the demand for household $i$ 's labour services,

$$
N_{t}^{i}=\left[\frac{W_{t}^{i}}{W_{t}}\right]^{-\theta} N_{t}
$$

where $N_{t}$ is the index of aggregate labour supply, and the aggregate wage index, $W_{t}$, is defined as,

$$
W_{t}=\left[\int_{0}^{1}\left(W_{t}^{i}\right)^{1-\theta_{w}} d i\right]^{\frac{1}{1-\theta_{w}}}
$$


While the utility of leisure is given by,

$$
v\left(N_{t}^{i}, \zeta_{t+1}\right)=\frac{e^{\zeta_{t+1}}\left(1-N_{t}^{i}\right)^{1-\eta}}{1-\eta} .
$$

We can then use the demand for labour, (23), and the definitions of the two felicities underpinning household utility, (19) and (25), to rewrite the objective function facing utility maximising wage-setters as,

$$
E_{t} \sum_{s=0}^{\infty}\left(\alpha_{w} \beta\right)^{s}\left[\begin{array}{c}
\frac{W_{t}^{o}}{P_{t+s}}\left[\frac{W_{t}^{o}}{W_{t+s}}\right]^{-\theta_{w}} \\
N_{t+s}\left(\begin{array}{c}
e^{\varepsilon_{t+s}}\left(\frac{c_{t+s}}{h_{t+s}^{u}}\right)^{-\rho} \frac{1}{h_{t+s}^{v}} \\
-\beta e^{\varepsilon_{t+s+1}} v\left(\frac{c_{t+s+1}}{h_{t+s+1}^{v}}\right)^{-\rho} \frac{c_{t+s+1}}{h_{t+s+1}^{1+v}}
\end{array}\right) \\
+\frac{e^{\zeta_{t+s}\left(1-\left[\frac{W_{t}^{o}}{W_{t+s}}\right]^{-\theta_{w}} N_{t+s}\right)^{1-\eta}}}{1-\eta}
\end{array}\right] .
$$

where $W_{t}^{o}$ is the nominal wage set in period $t$ by optimising wage-setters who are able to reset their wage in that period. The first-order condition obtained by maximising this objective function with respect to $W_{t}^{o}$ is given by,

$$
\begin{gathered}
E_{t} \sum_{s=0}^{\infty}\left(\alpha_{w} \beta\right)^{s}\left(\theta_{w}-1\right) W_{t}^{i}\left(W_{t+s}\right)^{\theta_{w}} P_{t+s}^{-1} N_{t+s} e^{\zeta_{t+s}} \\
{\left[e^{\varepsilon_{t+s}}\left(\frac{c_{t+s}}{h_{t+s}^{u}}\right)^{-\rho} \frac{1}{h_{t+s}^{v}}-\beta e^{\varepsilon_{t+s+1}} v\left(\frac{c_{t+s+1}}{h_{t+s+1}^{v}}\right)^{-\rho} \frac{c_{t+s+1}}{h_{t+s+1}^{1+v}}\right]=} \\
E_{t} \sum_{s=0}^{\infty}\left(\alpha_{w} \beta\right)^{s} e^{\varepsilon_{t+s}} \theta_{w}\left(W_{t+s}\right)^{\theta_{w}} N_{t+s} \\
{\left[1-\left(W_{t}^{i}\right)^{-\theta_{w}}\left(W_{t+s}\right)^{\theta_{w}} N_{t+s}\right]^{-\eta} .}
\end{gathered}
$$

We also allow for the possibility that not all workers follow this optimisation. Due to the costs of collecting and processing information, some workers may reset their wage according to simple rules of thumb. We follow Sbordone (2001) in assuming that the rule of thumb such workers use is to set their wage at the level of last year's reset wage increased to reflect the rate of wage inflation observed last year.

$$
W_{t}^{b}=W_{t-1}^{*}\left(1+\pi_{t-1}^{w}\right)
$$

where $W_{t}^{b}$ is the wage set by backward-looking rule-of-thumb wage setters this period, $W_{t-1}^{*}$ is the average wage set by those that where able to reset wages in the previous period, and $\pi_{t-1}^{w}$ is the rate of wage inflation in the previous period. This captures the idea that workers may differ in their abilities to forecast future economic conditions (see Sims (1998)), such that some workers essentially freeride on the efforts of others to set an optimal wage by implementing a rule based on wages set by others. Provided the proportion of households which set wages optimally is large enough then the costs of following this rule of thumb will be relatively small. Appendix 1 details the log-linearised dynamics of wage inflation after combining the wage-setting decisions of forward and backwardlooking wage setters. This yields the following Phillips curve for wage inflation,

$$
\widehat{\pi}_{t}^{w}=\frac{\beta \alpha_{w}}{\lambda_{w}} E_{t} \widehat{\pi}_{t+1}^{w}+\frac{\omega_{N}}{\lambda_{w}} \widehat{\pi}_{t-1}^{w}-\frac{\left(1-\omega_{w}\right)\left(1-\alpha_{w}\right)\left(1-\alpha_{w} \beta\right)}{\left(1+\eta \frac{\bar{N}}{1-\bar{N}} \theta_{w}\right) \lambda_{w}} \widehat{Z}_{t}
$$


where $\lambda_{w}=\omega_{w}+\beta \omega_{w} \alpha_{w}+\alpha_{w}-\omega_{w} \alpha_{w}$,

$$
\begin{aligned}
& \widehat{Z}_{t}=\left(\widehat{w}_{t}+\eta \frac{\bar{N}}{1-\bar{N}} \frac{\phi}{\phi-1}\left(\widehat{s}_{t}-\widehat{w}_{t}\right)-\frac{\rho+v \beta(v \rho-v-1)}{1+v \beta} \frac{\bar{y}_{\bar{c}}}{\bar{c}} \widehat{y}_{t}\right. \\
& +\frac{v \beta}{1+v \beta}(\rho-1) \frac{\bar{y}}{\bar{c}} E_{t} \widehat{y}_{t+1}+\frac{v}{1+v \beta}(\rho-1) \frac{\bar{y}}{\bar{c}} \widehat{y}_{t-1} \\
& \left.+\left(1+\frac{1}{1+v \beta}\right) \varepsilon_{t}-\zeta_{t}\right)
\end{aligned}
$$

and $\widehat{s}_{t}=\widehat{w}_{t}+\widehat{N}_{t}-\widehat{y}_{t}$ which reflects labour's share of income and is equivalent to the log-linearised marginal cost of production given our Cobb-Douglas production function, (8).

\subsection{Firms' Pricing Behaviour}

Firm $z$ is the monopolistic supplier of good $z$, which it produces according to the production function (8). In each period a proportion, $\left(1-\alpha_{P}\right)$, of firms are able to set a new price. Of these firms a proportion, $\left(1-\omega_{P}\right)$, set the new price by seeking to maximise the discounted value of profits, while the remainder follow a simple rule of thumb. By maximising the index (7) for a given level of consumption expenditure and aggregating across consumers, consumers' demand for the individual products that make up their consumption baskets is given by the following demand curve,

$$
c_{t}(z)=\left[\frac{p_{t}(z)}{P_{t}}\right]^{-\theta_{P}} c_{t}
$$

where the consumption-based price index, $P_{t}$, is defined as,

$$
P_{t}=\left[\int_{0}^{1} p_{t}(z)^{1-\theta_{p}} d z\right]^{\frac{1}{1-\theta_{p}}} .
$$

Aggregate demand for output is defined as $y_{t}=c_{t}+g_{t}$, where government spending is allocated across goods in the same pattern as consumption spending by maximising an index of the same form as (7). Therefore, the firms choosing the reset price optimally will choose a price, $P_{t}^{o}$, to maximise expected discounted value of profits generated across the expected life of that price contract,

$$
\begin{aligned}
& P_{t}^{o}\left(\frac{P_{t}^{o}}{P_{t}}\right)^{-\theta_{P}} y_{t}-W_{t}\left(\left(\frac{P_{t}^{o}}{P_{t}}\right)^{-\theta_{P}} y_{t} e^{-\mu_{t}}\right)^{\phi} \\
& +E_{t} \sum_{s=1}^{\infty} \frac{\alpha_{p}^{s} P_{t}^{o}\left(\frac{P_{t}^{o}}{P_{t+s}}\right)^{-\theta_{p}} e^{-\mu_{t+s}} y_{t+s}-W_{t+s}\left(\left(\frac{P_{t}^{o}}{P_{t+s}}\right)^{-\theta_{p}} e^{-\mu_{t+s}} y_{t+s}\right)^{\phi}}{\prod_{j=1}^{s} r_{t+j-1}}
\end{aligned}
$$


where $W_{t}$ is the index of the nominal wage rate in period t. The first-order condition for this optimisation is given by,

$$
\left(P_{t}^{o}\right)^{1+\theta_{p}(1-\phi)}=\frac{\theta_{p} P_{t}^{\theta_{p} \phi} w_{t} y_{t}^{\phi} e^{-\mu_{t} \phi}+E_{t} \sum_{s=1}^{\infty} \frac{\alpha_{p}^{s}\left(\theta P_{t+s}^{\theta p} w_{t+s} y_{t+s}^{\phi} e^{-\mu_{t+s} \phi}\right)}{\prod_{j=1}^{s} r_{t+j-1}}}{\left(\theta_{p}-1\right) P_{t}^{\theta_{p}-1} y_{t}+E_{t} \sum_{s=1}^{\infty} \frac{\alpha_{p}^{s}\left(\left(\theta_{p}-1\right) P_{t+s}^{\theta_{p}-1} y_{t+s}\right)}{\prod_{j=1}^{s} r_{t+j-1}}} .
$$

Analogous to the wage setting process, we also allow for the possibility that some firms reset prices by implementing a simple rule of thumb such that they set a price, $P_{t}^{b}$, equal to the average price set by those firms which adjusted price in the previous period, $P_{t-1}^{*}$, after inflating that price by the rate of inflation observed in the previous period,

$$
P_{t}^{b}=P_{t-1}^{*}\left(1+\pi_{t-1}^{p}\right)
$$

Appendix 2 details the log-linearisation of these pricing decisions, which yields a hybrid Phillips curve for price inflation of the following form,

$$
\widehat{\pi}_{t}^{p}=\frac{\beta \alpha_{p}}{\lambda_{p}} E_{t} \widehat{\pi}_{t+1}^{p}+\frac{\omega_{P}}{\lambda_{p}} \widehat{\pi}_{t-1}^{p}+\frac{\left(1-\omega_{P}\right)\left(1-\alpha_{P}\right)\left(1-\alpha_{P} \beta\right)}{\left(1+(\phi-1) \theta_{P}\right) \lambda_{p}} \widehat{s}_{t}
$$

where $\lambda_{p}=\omega_{p}+\beta \omega_{p} \alpha_{p}+\alpha_{p}-\omega_{p} \alpha_{p}$, and $\widehat{s}_{t}=\widehat{w}_{t}+\widehat{N}_{t}-\widehat{y}_{t}$. This hybrid Phillips curve is the same as that derived in Gali et al (2001).

The model derived in this section can now be seen to incorporate a number of interesting effects within a micro-founded general equilibrium framework, such that the theoretical models underpinning the empirical studies discussed in the introduction are often special cases of our model. By encompassing existing studies and subjecting the model to conventional econometric estimation, we shall be able to discriminate between competing representations of the NNCS. This is the subject of the next section.

\section{Econometric Method, Results and Simulations}

In this Section we first set out the methods employed to estimate the parameters of the model derived in Section 2 for the US and Europe. We next examine the robustness of these estimates and discuss them in the context of findings from other partial and general equilibrium studies. This discussion allows us to draw a number of useful conclusions of direct relevance to policy makers. Finally we analyse the response of our model to monetary policy shocks as a means of assessing the importance of the various monetary transmission mechanisms linking the interest rate instrument with the real and nominal economies, and the differences in estimated parameters across the US and Europe.

\subsection{Estimation Method}

The general equilibrium model which we estimate consists of three equations. These include the Euler equation for output in the presence of habits (i.e. equation (21)) and two Phillips curves describing the dynamic path of wage and price 
inflation (i.e. equations (29) and (36)). Given that our model incorporates forward looking rational expectations (RE) and since we wish to conduct policy analysis using the estimated 'deep parameters', we employ Hansen's (1982) generalised method of moments (GMM) estimator. The RE hypothesis suggests a set of orthogonality conditions that can be naturally handled within the GMM framework. To illustrate how we apply GMM to obtain parameter estimates and specification consistent standard errors, consider the following system of nonlinear equations given by (21), (29) and (36).

$$
\mathbf{y}_{t}=\mathbf{f}\left(\boldsymbol{\theta}, \mathbf{x}_{t}\right)+\mathbf{u}_{t}
$$

where $\mathbf{y}_{t}$ is a $(3 \mathrm{x} 1)$ vector of dependent variables, $\left[\widehat{\pi}_{t}^{p}, \widehat{\pi}_{t}^{w}, \widehat{y}_{t}\right]^{\prime}$ or equivalently $\left[f_{1}\left(\boldsymbol{\theta}_{1}, x_{1 t}\right)+u_{1 t} ; f_{2}\left(\boldsymbol{\theta}_{2}, x_{2 t}\right)+u_{2 t} ; f_{3}\left(\boldsymbol{\theta}_{3}, x_{3 t}\right)+u_{3 t}\right]^{\prime} ; \boldsymbol{\theta}$ is the $(16 \mathrm{x} 1)$ vector of unknown parameters, $\left[\boldsymbol{\theta}_{1}\left(=\alpha_{p}, \omega_{p}, \theta_{p}, \beta, \phi\right) ; \boldsymbol{\theta}_{2}\left(=\alpha_{e}, \omega_{w}, \theta_{w}, \beta, \phi, \eta, v, \rho ; \boldsymbol{\theta}_{3}(=\right.\right.$ $\beta, v, \rho)]^{\prime} ; \mathbf{x}_{t}$ is the $(12 \mathrm{x} 1)$ vector of explanatory variables, $\left[x_{1 t}\left(=\widehat{\pi}_{t+1}^{p}, \widehat{\pi}_{t-1}^{p}, \widehat{s}_{t}\right)\right.$; $\left.x_{2 t}\left(=\widehat{\pi}_{t+1}^{w}, \widehat{\pi}_{t-1}^{w},\left(\widehat{s}_{t}-\widehat{w}_{t}\right), \widehat{y}_{t+1}, \widehat{y}_{t-1}\right) ; x_{3 t}\left(=\widehat{y}_{t+2}, \widehat{y}_{t+1}, \widehat{y}_{t-1},\left\{r_{t}-\widehat{\pi}_{t+1}^{p}\right\}\right)\right]^{\prime} ;$ and $\mathbf{u}_{t}$ is the $(3 \times 1)$ vector of errors $\left[u_{1 t}, u_{2 t}, u_{3 t}\right]^{\prime}$.

The $r$ orthogonality conditions for our model can be written as follows

$$
\mathbf{h}\left(\boldsymbol{\theta}, \mathbf{w}_{t}\right)=\left[\begin{array}{l}
E_{t}\left[y_{1 t}-f_{1}\left(\boldsymbol{\theta}, \mathbf{x}_{t}\right)\right] \mathbf{z}_{t}=0 \\
E_{t}\left[y_{2 t}-f_{2}\left(\boldsymbol{\theta}, \mathbf{x}_{t}\right)\right] \mathbf{z}_{t}=0 \\
E_{t}\left[y_{3 t}-f_{3}\left(\boldsymbol{\theta}, \mathbf{x}_{t}\right)\right] \mathbf{z}_{t}=0
\end{array}\right]
$$

where $f_{i}\left(\boldsymbol{\theta}, \mathbf{x}_{t}\right)$ denotes the $i^{\text {th }}$ element of $\mathbf{f}\left(\boldsymbol{\theta}, \mathbf{x}_{t}\right) ; \mathbf{w}_{t} \equiv\left(\mathbf{y}_{t}^{\prime}, \mathbf{x}_{t}^{\prime}, \mathbf{z}_{t}^{\prime}\right)^{\prime} ; \mathbf{z}_{t}$ is a $(20 \mathrm{x} 1)$ vector of instruments ${ }^{8},\left[\widehat{\pi}_{t-1}^{p} \ldots \widehat{\pi}_{t-4}^{p}, \widehat{\pi}_{t-1}^{w} \ldots \widehat{\pi}_{t-4}^{p}, \widehat{s}_{t} \ldots \widehat{s}_{t-4}, \widehat{y}_{t} \ldots \widehat{y}_{t-4}\right.$, $\widehat{\pi}_{t-1}^{c} \ldots \widehat{\pi}_{t-1}^{c}$, constant term] $]^{\prime} ; \widehat{\pi}^{c}$ refers to commodity price inflation and we assume that $E_{t}\left(\mathbf{z}_{t}, \mathbf{u}_{t}\right)=0$.

Given the above setup we obtain the GMM estimate of the unknown parameter vector $\boldsymbol{\theta}$ as the value that minimizes

$$
Q=\left(\boldsymbol{\theta} ; \mathbf{Y}_{T}\right)=\left[(1 / T) \sum_{t=1}^{T} \mathbf{h}\left(\boldsymbol{\theta}, \mathbf{w}_{t}\right)\right]^{\prime} \widehat{S}_{T}^{-1}\left[(1 / T) \sum_{t=1}^{T} \mathbf{h}\left(\boldsymbol{\theta}, \mathbf{w}_{t}\right)\right] .
$$

where $\widehat{S}_{T}^{-1}$ is an estimate of the inverse of the covariance matrix of sample moments. Since our theory imposes a common $\beta$ across all three equations,

\footnotetext{
${ }^{8}$ Our instruments set is based on the one used in Galí and Gertler (1999). We conduct Hansen's J-test to test the validity of our overidentifying restrictions since we have more instruments than parameters to estimate. Given that this test uses up many degrees of freedom, e.g. $J^{\sim} \chi^{2}(r-a)$ it may be possible to achieve more power by reducing the number of degrees of freedom (see Davidson and MacKinnon, op cit, pp 616). In our model $r=3 \cdot(5 \cdot 4+1)$, (i.e. 3 equations, 5 variables, 4 lags and a constant). In an attempt to increase the power of this test, our instrument set $\mathbf{z}_{t}$ does not include four lags of the spread between the long and short interest rate used in Galí and Gertler (1999). We also experimented with alternative subsets of our instrument set $\mathbf{z}_{t}$ employing as few as 12 regressors and found that the J-test was robust, i.e. we could not reject the validity of these alternative instrument sets. Additionally, the parameter estimates associated with these were reasonably robust. However, none of the alternative sets employed yielded standard errors which were as efficient as those obtained by using the instruments currently defined in $\mathbf{z}_{t}$. The results based on the alternative sets will be made available on request.
} 
a common $\phi$ across the two inflation equations and a common $\nu$ across the wage inflation and Euler equations we have in effect 11 unique parameters to estimate. Given the dimension of $\mathbf{x}_{t}$ this implies that we must condition our estimations on at least one restricted parameter. Moreover formal identification additionally necessitates satisfaction of order and rank conditions. The order condition requires that $(r \geq a)$, and the rank, discussed further below, that the columns of the plim of $\widehat{D}_{T}^{\prime}$ be linearly independent, where

$$
\widehat{D}_{T}^{\prime}=\left.(1 / T) \sum_{t=1}^{T} \frac{\partial \mathbf{h}\left(\boldsymbol{\theta}, \mathbf{w}_{t}\right)}{\partial \boldsymbol{\theta}^{\prime}}\right|_{\boldsymbol{\theta}=\hat{\boldsymbol{\theta}}_{T}} .
$$

\subsection{Estimation Results ${ }^{9}$}

We next report the result of estimating the elements of $\boldsymbol{\theta}$ for the US and the Euro Area over the period 1970.1 to $1998.2^{10}$. Note that all of the model's variables expressed as rates are transformed to deviations from steady-state by removing their mean prior to estimation, whereas a deterministic polynomial time trend is removed from the levels variables. Further note that while the rank condition is clearly satisfied for our model, extensive numerical examination of the columns of $\widehat{D}_{T}^{\prime}$ indicated that the imposition of any four elements of the parameter vector $\theta$ is required before a stable solution to the minimisation of (39) can be achieved. In selecting which parameters to restrict, we have chosen to condition on values which appear to be widely accepted in the literature and/or have also been employed in other conditional estimations. For example, the results reported in this Section are based on values of $\theta_{p}=\theta_{w}=11, \eta=1.5$ and $\phi=1.66$ (for the US) and 1.47 (for Europe). The values of $\theta_{p}$, and $\phi$ are taken from Galí et al 2001 who also estimate a price hybrid NKPC conditioned on these values. Our value of $\eta$ of 1.5 is taken from Erceg et al (2000). Finally, we also follow Erceg et al (op. cit.) in assuming that $1 / 3$ of workers' productive time is spent working, the remaining $2 / 3$ in leisure such that $\bar{N} /(1-\bar{N})=1 / 2$. We also assume that the share of consumption in output, $\bar{c} / \bar{y}$ is 0.81 as in McCallum and Nelson (1998). This value is also consistent with estimates for a typical OECD economy provided by Galí (1994) once it is recognised that our definition of government spending does not include transfers ${ }^{11}$

\footnotetext{
${ }^{9}$ All of the econometric estimation is carried out using TSP Version 4.5.

${ }^{10}$ The US and Euro area data we employ were kindly supplied by Jordi Galí, Mark Gertler and David López-Salido. The US data is described in Gali Gertler (1999) and the Euro area data in Gali et (2001). The original source for the Euro area data is Fagan et al (2001).

${ }^{11}$ Note that our $\phi$ is equivalent to the Gali et al $1 /(1-\alpha)$, where $(1-\alpha)$ is the elasticity of output with respect to employment and is 0.4 and 0.32 for the US and Europe respectively. Additionally our $\theta_{p}$ is equal to the Gali et al $\varepsilon=\mu /(\mu-1)$ where $\mu$ is the price mark-up $(=1.1)$ for the US and Europe. We further assume the $\theta_{p}=\theta_{w}$ since there is no obvious reason to assume different degrees of market power in the labour and product markets. Finally note that we considered the robustness of our results to changes in these imposed paraneters, by allowing $\theta_{p}$ and $\theta_{w}$ to vary between 4 and 21 . These values cover a range found in other econometric or calibration studies, see, for example, Erceg et al (op. cit.) who set $\theta_{p}=\theta_{w}=4$ and Erceg et al (op. cit.) who assess the robustness of their results by imposing $\theta_{p}=21$. We
} 
Given that it is possible to calculate a heteroscedastic, autocorrelation consistent (HAC) matrix $\widehat{S}$, in the GMM framwork and since this estimator clearly dominates its rivals when both problems are present (see Andrews 1991)), we first check the properties of the errors resulting from the GMM estimation of our 3-equation system to see if this is required. A further important reason for checking the properties of the errors relates to another of Andrew's findings. That is, none of the HAC estimators he considers is reliable for sample sizes up to 250 if the errors follow an $\mathrm{AR}(1)$ process with an autocorrelation parameter greater than 0.90 .

Table 1: Autocorrelations

\begin{tabular}{|c|c|c|c|c|c|c|}
\hline \multicolumn{4}{|c|}{ US (Price Inflation) } & \multicolumn{3}{|c|}{$\begin{array}{c}\text { Europe (Price Inflation) } \\
\end{array}$} \\
\hline Lag $k$ & $\operatorname{AR}(k)$ & $Q$-Stat & Prob & $\operatorname{AR}(k)$ & $Q$-Stat & Prob \\
\hline 1 & -0.44 & 22.44 & 0.000 & -0.38 & 15.90 & 0.000 \\
\hline 4 & 0.13 & 24.86 & 0.000 & 0.15 & 25.23 & 0.000 \\
\hline 8 & 0.10 & 32.69 & 0.000 & 0.15 & 30.49 & 0.000 \\
\hline 12 & -0.07 & 34.94 & 0.000 & 0.08 & 32.21 & 0.001 \\
\hline \multicolumn{4}{|c|}{ US (Wage Inflation) } & \multicolumn{3}{|c|}{ Europe (Wage Inflation) } \\
\hline Lag $k$ & $\operatorname{AR}(k)$ & $Q$-Stat & Prob & $\operatorname{AR}(k)$ & $Q$-Stat & Prob \\
\hline 1 & -0.57 & 36.74 & 0.000 & -0.46 & 23.60 & 0.000 \\
\hline 4 & 0.10 & 40.64 & 0.000 & 0.20 & 32.11 & 0.000 \\
\hline 8 & 0.14 & 58.98 & 0.000 & 0.02 & 33.83 & 0.000 \\
\hline \multirow[t]{2}{*}{12} & 0.12 & 61.27 & 0.000 & -0.16 & 50.14 & 0.001 \\
\hline & \multicolumn{3}{|c|}{ US (Output) } & \multicolumn{3}{|c|}{ Europe (Output) } \\
\hline Lag $k$ & $\operatorname{AR}(k)$ & $Q$-Stat & Prob & $\operatorname{AR}(k)$ & $Q$-Stat & Prob \\
\hline 1 & 0.27 & 8.51 & 0.004 & -0.06 & 0.38 & 0.537 \\
\hline 4 & 0.05 & 12.82 & 0.012 & 0.20 & 19.49 & 0.001 \\
\hline 8 & -0.29 & 25.92 & 0.001 & -0.03 & 20.10 & 0.007 \\
\hline 12 & -0.23 & 33.27 & 0.001 & -0.16 & 24.46 & 0.018 \\
\hline
\end{tabular}

Notes: (i) $\operatorname{AR}(k)$ is the autocorrelation coefficient for the errors at lag k; (ii) the $Q$ statistic at lag $k$ is a test statistic for the null hypothesis that there is no autocorrelation up to order $k$ (see Ljung and Box (1979)), $Q^{\sim} \chi^{2}(k)$; and (iii) US sample: 70.1-97.4; EU sample: 71.2-97.4.

also varied the labour supply parameter, $\eta$ between 0.5 and 4 , which encompasses the values of $\eta$ assumed in a number of studies, including $\eta=1$ a value commonly imposed by adopting a logarithmic utility function in RBC models following Prescott (1986). In all cases varying the imposed parameters in these ways did not materially affect the results of our estimation. 
Table 2: Variance of Errors

\begin{tabular}{lclccc}
\hline \hline \multirow{2}{*}{ US (70.1-97.4) } & constant & $T$ & $T^{2}$ & $T^{3}$ & $\chi^{2}(1)$ \\
Price Inflation & 0.11 & -0.001 & - & - & 15.73 \\
& $(0.000)$ & $(0.000)$ & - & - & - \\
Wage Inflation & 0.83 & -0.041 & 0.001 & $-3.8 \mathrm{E}-6$ & 15.50 \\
& $(0.000)$ & $(0.000)$ & $(0.002)$ & $(0.007)$ & - \\
Output & 1.76 & -0.016 & - & - & 10.63 \\
Europe (71.2-97.4) & $(0.000)$ & $(0.001)$ & - & - & - \\
Price Inflation & 0.16 & -0.001 & - & - & 14.19 \\
Wage Inflation & $(0.000)$ & $(0.000)$ & - & - & - \\
& 0.54 & -0.002 & - & - & 0.57 \\
Output & $(0.001)$ & $(0.453)$ & - & - & - \\
& 0.28 & -0.001 & - & - & 0.79 \\
& $(0.000)$ & $(0.38)$ & - & - & - \\
\hline
\end{tabular}

Notes: (i) the dependent variable for the ancillary regressions reported above is the square of the residuals from the GMM estimation of the 3-equation system; (ii) the White (1980) test is calculated as $N \cdot\left(R^{2}\right)^{\sim} \chi^{2}(1)$; (iii) the critical value of $\chi^{2}(1)=$ 3.84 ; and (iv) the numbers in parentheses are p-values.

The results reported in Table 1 clearly show that while there is significant serial correlation in the errors of all 3 equations they are all stationary. Additionally Table 2 indicates that there does not appear to be heteroscedasticity in the errors of the European wage inflation and output equations of the simple form tested for. However visual inspection of the plots of the residuals squared over time clearly suggests that: (i) the wage inflation error variance post 1983 is greater than the pre-1983 period; and (ii) the error variance for output post 1983 is greater than the pre-1983 period, especially when account is taken of the outlying observations in 1974 and $1981^{12}$. Given these results, to obtain standard errors which are robust to heteroscedasticity and autocorrelation of unknown form, we calculate $\widehat{S}$ using the Newey and West (1987) estimator, e.g.

$$
\widehat{S}_{T}=\widehat{\Gamma}_{0, T}+\sum_{v=1}^{q}\{1-[v /(q+1)]\}\left(\widehat{\Gamma}_{v, T}+\widehat{\Gamma}_{v, T}^{\prime}\right)
$$

where

$$
\widehat{\Gamma}_{v, T}=+(1 / T) \sum_{t=v+1}^{T}\left[\mathbf{h}\left(\widehat{\boldsymbol{\theta}}, \mathbf{w}_{t}\right)\right]\left[\mathbf{h}\left(\widehat{\boldsymbol{\theta}}, \mathbf{w}_{t-v}\right)\right]^{\prime}
$$

\footnotetext{
${ }^{12}$ In the interests of preserving space, we have not included these plots but will provide
} them on request. 
and $q$ is the lag truncation parameter ${ }^{13}$.

The results of our estimation are reported in Table 3.

Table 3: GMM Parameter Estimates

$\underline{\mathrm{US}\left(\theta_{p}=\theta_{w}=11, \eta=1.5, \phi=1.66\right)}$

\begin{tabular}{cccccccc}
\hline \hline \multicolumn{8}{c}{ Parameters } \\
$\alpha_{p}$ & $\omega_{p}$ & $\alpha_{w}$ & $\omega_{w}$ & $v$ & $\beta$ & $\rho$ & J.Test \\
0.51 & 0.83 & 0.88 & 0.175 & (n/a) & 0.83 & 7.54 & 12.67 \\
{$[0.188]$} & {$[0.161]$} & {$[0.026]$} & {$[0.031]$} & (n/a) & {$[0.016]$} & {$[2.71]$} & \\
\hline
\end{tabular}

Euro Area $\left(\theta_{p}=\theta_{w}=11, \eta=1.5, \phi=1.47\right)$

\begin{tabular}{cccccccc}
\hline \hline \multicolumn{7}{c}{ Parameters } \\
$\alpha_{p}$ & $\omega_{p}$ & $\alpha_{w}$ & $\omega_{w}$ & $v$ & $\beta$ & $\rho$ & J.Test \\
0.66 & 0.19 & 0.74 & 0.11 & 0.34 & 0.74 & 7.5 & 12.43 \\
{$[0.010]$} & {$[0.016]$} & {$[0.012]$} & {$[0.021]$} & {$[0.014]$} & {$[0.014]$} & $(\mathrm{n} / \mathrm{a})$ & \\
\hline
\end{tabular}

Notes: (i) the $R^{2}$ 's for the US price and wage inflation and output equations are 0.86 , 0.55 and 0.86 respectively; (ii) the $R^{2}$ 's for the European price and wage inflation and output equations are $0.89,0.69$ and 0.92 respectively; (iii) the critical value of $\chi^{2}(r-a)=75.8$ where $r-a=57$; (iv) the numbers in square brackets are HAC standard errors.

Aside from differences in estimated parameter values (which we discuss below), the estimations differ between the two economies in two ways. Firstly, we were unable to estimate a value of $\rho$ for Europe which was both statistically significant and of a believable magnitude. Secondly, we could not find any evidence of significant habits effects in the US data once we impose the constraint that $v<1$. This condition is necessary to avoid the undesirable property that steady-state utility is decreasing in consumption.

The problem of finding significant real interest rate effects in output equations is well known. Fair (2001), for example, estimates equations for various components of aggregate demand using real and nominal interest rates for a variety of economies. What is interesting about these results, as far as the present study is concerned, is that only the US, Canada and India were significant real interest rate effects on consumption found. For most European economies there is little evidence of real interest rate effects on consumption, although the impact of real rates on investment is greater. This may explain why the coefficient on the real interest rate term in the Euler equation was poorly determined in

\footnotetext{
${ }^{13}$ In the estimations reported in Table 3 , the value of $q$ is equal to 8 . Note that we use the Bartlett spectral density kernal to insure the positive definiteness of the covariance matrix of the orthogonality conditions (see Newey and West, 1987). Further note that these results are extremely robust to alternative values of $q$, e.g. we examined values ranging from 4 to 12 . To preserve space, these results are not reported but will be made available from the authors on request.
} 
Europe. As a result, we condition our European estimates on a value of $\rho$ equal to 7.54, as this is consistent with the estimated value for the US and implies a modest response of output to changes in interest rates. We should add here that our results were robust to changes in this imposed parameter, e.g. we considered values of $\rho$ lying between 4 and 10 without materially affecting the results of our estimated parameters ${ }^{14}$.

\subsubsection{Interpretation of Estimated Parameters}

We now turn to consider the economic interpretation of our estimated parameter values in the US and Europe. The estimated value of $\alpha_{p}$ of 0.66 for Europe indicates that it takes on average 9 months for firms to reset their prices, while in the US the estimated parameter value of 0.51 suggests that the degree of inertia in prices is lower with prices being reset after 6 months, on average. Our findings regarding the average length of time taken to adjust prices in the US is broadly consistent with survey evidence. For example, Blinder (1994) finds that prices remained fixed for an average of 9 months in the US. Carlton (1986) found that prices in his sample remained fixed from between 4 and 13 months in his sample depending on the particular product. Kashyap (1995) examined products listed in the L.L.Bean catalogue and found that these prices were held fixed from between 11 and 30 months. Our estimate for the US is slightly lower than these figures at just over 6 months. They are, however, consistent with the estimates of Galí and Gertler (2001) for both the US and Europe. We also estimate equivalent parameters in our Phillips curve describing the dynamics of wage inflation. The estimated value of $\alpha_{w}$ in Europe of 0.74 implies that the average length of wage contracts in Europe are one year, while the corresponding estimate for the US of 0.88 implies an average contract length of approximately two years. There is less evidence on the average length of labour contracts in the US and Europe. However, most labour contracts in Europe are negotiated annually in contrast to the US where 3-year wage contracts are more prevalent (see Bruno and Sachs (1985), pp. 245 and 247). This suggests that our average figure of 2 years for the US and 1 year for Europe are not inconsistent with the stylised facts.

The estimated parameter, $\omega_{p}$, measures the proportion of firms which utilise a simple backward-looking rule of thumb when resetting their price, rather than attempting to maximise discounted profits. It should be pointed out that although this rule of thumb does not emerge from an explicit maximisation, it will lead to rule-of-thumb firms adopting the profit maximising price in the long-run provided a sufficient number of firms set prices optimally. Here our estimates imply that $18.5 \%$ of firms in Europe follow the rule-of-thumb behaviour, while $31 \%$ of firms in the US do so. One possible explanation for this finding is that since prices are reset less frequently in Europe the costs of failing to reset that price optimally are greater. In contrast, in the US, since prices are reset with greater frequency it may be more costly for firms to collect the information to

\footnotetext{
${ }^{14}$ Note that we discuss the results for other empirical studies in the next subsection.
} 
reset prices optimally every time. The extent of backward looking behaviour in price setting that we find is also consistent with the parameter estimates of Galí et al (2001). This is in contrast to reduced form estimates of the hybrid Phillips curve for inflation which use the output gap as its measure of marginal costs (see, for example, Fuhrer and Moore (1995) or Chadha et al (1992)). Since output appears to lead inflation in the raw data, simple regressions of the change in inflation on an output gap yield a significant positive coefficient (see Galí and Gertler (1999) and Mankiw (2000) for a discussion of this point) suggesting that a backward-looking Phillips curve fits the raw data better than the basic forward-looking NKPC. In estimates of the hybrid NKPC Phillips curve this then manifests itself by placing a greater weight on the backward-looking specification implying an implausible degree of backward-looking behaviour. The problem with these estimates is that they are generated by a mis-specified model to the extent that the output gap is not an accurate measure of marginal costs. Our finding of significant inertia in wage setting in both the US and Europe, and the presence of habits in consumption/labour supply in Europe implies that the output gap is not proportional to marginal costs. Accordingly estimates of Phillips curves which rely on output gaps as their measure of marginal costs tend to overestimate the degree of backward looking behaviour in price setting.

We also provide an estimate of the proportion of wage contracts which are set to maximise workers' utility and the number based a simple backward-looking rule-of-thumb, $\omega_{w}$. The proportion of rule-of-thumb wage setters are $11 \%$ and $17.4 \%$ in the Europe and the US respectively. Here the extent of backwardlooking behaviour in both economies is even lower than in the case of price setting. This could reflect the fact that a firm could be pricing a range of products such that the price charged on a specific product may not materially affect the firm's profits, thereby allowing the firm to follow a rule-of-thumb which allows them to free-ride on the optimal price-setting behaviour of others. This is then reinforced by the fact that the price is unlikely to remain in force for longer than 9 months in Europe or 6 months in the US. In the case of wage setting, however, workers do not typically provide labour to more than one firm and the wage they negotiate is likely to remain in place for at least one year (possibly longer in the US), and so any mispricing of their labour is likely to materially affect their utility. Accordingly wage setting behaviour attempts to maximise utility whenever there is the opportunity to reset the wage. The fact the extent of backward-looking wage setting behaviour is lower in Europe than the US, even although contracts last longer in the US is also worthy of comment. One possible explanation for this is that the prevalence of collective bargaining in Europe reduces the costs per worker of collecting the information necessary to negotiate an optimal wage.

Our estimation also generates estimates of three other structural parameters. Firstly the parameter, $\rho$, which implies an intertemporal elasticity of substitution of consumption of $\frac{1}{\rho}$. Our estimate of $\rho$ for the US of 7.5 is consistent with other empirical studies. For example, McCallum and Nelson (1998) estimate a value of $\rho$ of 5 , while Rotemberg and Woodford (1997) estimate $\rho$ to be 6.25 
and Fuhrer (2000) estimates $\rho$ to lie in the range 6 to 13.1. Secondly we estimate $v$ which captures the extent to which past consumption, affects current consumption and labour supply decisions. A value of zero indicates that there are no 'habits' effects in our model, while a value of 1 suggests that it is only the value of current consumption relative to past consumption that matters the level of consumption is unimportant. The value of 0.34 for Europe provides evidence of habits in consumption, although this is lower than some estimates of the importance of habits in single equation estimates of consumption equations (see, for example, Fuhrer's (2000) results for the US). The final parameter we estimate is $\beta$, the discount factor in each economy. Our estimation implies estimates of $\beta$ of 0.83 in the US and 0.74 in Europe, which are in line with the estimates of $\beta$ for the US in Galí et al (2001), but slightly lower than their European estimates. Overall these estimates of $\beta$ imply that consumers' rate of time preference is fairly high. However, what the data may be picking up here are mark-ups over the real rate of interest arising from uncertainty not explicitly included in our model. For example, the presence of finite lives will tend to raise the rate at which consumers discount future labour income above the risk-free rate of interest. Accordingly our estimates of $\beta$ not only reflect the consumers' rate of time preference which implies an equilibrium risk-free real interest rate, but also implicitly includes risk premia reflecting risks not formally included in our model.

\subsection{Simulations}

The model estimated in the previous subsection contains dynamic equations for wage and price inflation, (equations (29) and (36)) and output (equation (21)). There are also technical relationships and identities implied by our theory which link these equations: the production function, $\widehat{y}_{t}=\frac{1}{\phi} \widehat{N}_{t}$, the labour share of output $\widehat{s}_{t}=\widehat{w}_{t}+\widehat{N}_{t}-\widehat{y}_{t}$, the real wage, $\widehat{w}_{t}=\widehat{W}_{t}-\widehat{P}_{t}$, and the evolution of nominal wages, $\widehat{W}_{t}=\widehat{W}_{t-1}+\widehat{\pi}_{t}^{w}$ and the price level, $\widehat{P}_{t}=\widehat{P}_{t-1}+\widehat{\pi}_{t}^{p}$. The model is then closed by specifying a rule for policy. For the purposes of illustration we adopt a Taylor rule for monetary policy (see Taylor (1993)),

$$
\widehat{R}_{t}=E_{t} \widehat{\pi}_{t+1}+\frac{1}{2} \widehat{\pi}_{t}+\frac{1}{2} \widehat{y}_{t}
$$

which indicates that the monetary authorities adjust nominal interest rates, $\widehat{R}_{t}$ such that real rates rise in response to excess inflation and positive output gaps. We then assume that the economy was initially in equilibrium before the monetary authorities unexpectedly raise nominal interest rates over and above the level implied by the Taylor rule by 1 point for 1 year. The paths for output, price and wage inflation for the US and Europe in the face of this shock are given in column 1 of Figure $1^{15}$.

\footnotetext{
${ }^{15}$ Given that our model has forward expectations, we require a solution algorithm which allows us to impose model consistent expectations. We carry out our simulations using WinSolve, Version 3 (see Pierse, (2000)) using the Stacked Newton solution method (see Boucekkine, (1995)).
} 


\section{\{Insert Figure 1 around here.\}}

The differences in the paths of variables between the US and Europe, reflect the differences in the estimated parameters for the two economies. Prices adjust faster in the US than in Europe, while the opposite is true of wages. However, despite the fact that price inertia is greater in Europe, output does not fall by as much in Europe relative to the US economy. This reason for this is the presence of habits in consumption, reducing the fall in consumption following the tightening of monetary policy. The size of this effect is revealed by the second column which plots the paths for the same variables for Europe in the face of the same shock, with and without habits effects in consumption. In the absence of habits the initial fall in consumption is greater and as a result both wages and prices are forced to adjust by more. By comparing column 1 with column 2 this suggests that most of the differences in price and wage adjustment are not due to differences in the degree of nominal inertia between the US and Europe, but are actually capturing real inertia in the European economy, which in our model enters through habits effects.

To examine the importance of backward looking behavior in the model, we set the proportion of backward-looking price and wage setters in both economies to zero. In other words we now have purely forward-looking wage and price setting in both economies. As we can see from the graphs in column 3 , the impact on the real economy is negligible, and although there are differences in the paths for wage and price inflation, these differences appear to be quantitatively small, particularly in the case of wage inflation. Accordingly it appears to be the case that the New Keynesian Phillips curve captures movements in the data well, especially once it is recognised that it applies to wages as well as prices, and that the European economy may also feature some real inertia in the form of habits effects in consumption.

Finally, there are several aspects to note about the dynamic paths of the variables in our model following this monetary policy shock. The first is that the magnitude of responses of output and inflation to this shock are in line with studies based on the VAR methodology (see, for example, Christiano et al (2001)) as well as simulations from large-scale macroeconometric models (see for example McKibbin and Sachs (1991)). However, while the dynamic paths of these variables in response to a monetary shock are relatively smooth, they do not follow the slow 'hump-shaped' responses reported in these VAR-based studies. While our model is in principle capable of generating such responses to monetary shocks, it would require a much stronger degree of habits and backward-looking behaviour in price and wage setting than we found in our econometric work $^{16}$. It appears therefore that the VARs tend to overestimate

\footnotetext{
${ }^{16}$ VAR analyses of the monetary policy transmission mechanism, based on correlations of inflation, output gaps and interest rates, often suggest that the peak response of inflation to a monetary shock comes two years after the shock (see, for example, Mankiw (2000) for a discussion of the evidence underlying this stylized fact). The peak inflation response is led by the peak response of output which is greatest after around one year. Our model can generate these results for both countries, but only if the proportion of wage and price-setters
} 
the extent of inflation inertia since they employ output gaps as a proxy for movements in marginal costs.

\section{Summary and Conclusions}

Recent work by Galí and Gertler (1999) and Galí et al (2001) has pointed out that previous estimates of hybrid NKPCs have been mis-specified by basing their measure of marginal costs on the output gap. As a result, specifications based on output gap measures have tended to overestimate the extent of backward-looking behaviour. Based on this insight, we derive and estimate general equilibrium models for the evaluation of monetary policy which are similar in structure to the benchmark mark model of the NNCS (Goodfriend and King, op. cit.). Our work extends the basic benchmark model by allowing for a number of potential channels which could explain the link between the output gap and marginal costs. For example, we first allow for the possibility that it is not only prices, but also wages which are sticky. Second we model the extent to which some economic agents use backward-looking rules of thumb when setting wages and/or prices, while others attempt to maximise lifetime utility or discounted profits. Finally, we introduce habits into consumption to allow for inertia in output.

Our estimates of these models produce a number of interesting results. For example, we find that there is more price stickiness in Europe than in the US, with prices taking on average 9 months and 6 months, respectively to adjust. In the case of wages, wage contracts in Europe typically last for one year, while our estimates imply average contract lengths of two years in the US, perhaps reflecting the significant number of three-year contracts in the US labour market. In both wage and price setting there is evidence of a statistically significant level of backward-looking behaviour. US price setters are more likely to use a rule-of-thumb than their European counterparts, possibly reflecting the costs of obtaining information necessary to reset prices optimally when that price is unlikely to remain in place for long. In contrast, wage setters in Europe are less likely to be backward looking than in the US. This may reflect the prevalence of collective-bargaining procedures in Europe relative to the US. We also found evidence of significant habits effects in consumption in Europe.

Finally we considered the response of each economy to a monetary policy shock in the form of a temporary rise in nominal interest rates. Here our results indicated that the presence of backward-looking behaviour in wage and price setting had only a very small effect on the paths of real and nominal variables in our economies, leading us to conclude that the NKPC provides is a reasonable description of inflation dynamics. This also suggests that empirical evidence on the degree of inertia in the economy derived from correlations of output gaps and inflation may significantly overestimate the degree of backward-looking be-

are imposed at $95 \%$, while the coefficient on habits is set at $v=0.9$. Not surprisingly, it is easy to show that these parameters are statistically different from our estimated parameters, whether we test their imposition individually or collectively. 
haviour in price and wage setting. We also found that the existence of significant habits effects in consumption accounted for more of the differences in response to the monetary policy shock between Europe and the US than any differences in the degree of nominal inertia in either wages or prices. Therefore, to the extent that these habits effects are capturing real inertia in the European economy this may explain a key difference in the responses of the two economies to monetary policy. 


\section{References}

[1] Amato, J. D. and T. Laubauch (2001), 'Estimation and Control of an Optimixation-Based Model with Sticky Prices and Wages', Journal of Economic Dynamics and Control, forthcoming.

[2] Andrews, D.W.K. (1991), 'Heteroskedasticity and Autocorrelation Consistent Covariance Matrix Estimation', Econometrica, 59, pp 817-58.

[3] Blinder, A. S. (1994), 'On Sticky Prices: Academic Theories Meet the Real World', In Monetary Policy, N. G. Mankiw ed., Pub Chicago University Press.

[4] Boucekkine, R. (1995) 'An Alternative Methodology for Solving Nonlinear Forward-Looking Models', Journal of Economic Dynamics and Control, 19, 711-734.

[5] Bruno, M. and J.D. Sachs (1985) Economics of Worldwide Stagflation, Harvard University Press, Cambridge, MA.

[6] Calvo, G. (1983), 'Staggered Prices in a Utility Maximising Framework', Journal of Monetary Economics, 12(3), pp 383-398.

[7] Carlton, D. W. (1986), 'The Rigidty of Prices', American Economic Review, 76(4), pp637-658.

[8] Carroll, C. D. (2000), 'Solving Consumption Models with Multiplicative Habits', Economics Letters, No. 68, pp. 67-77.

[9] Chadha, B., P. R. Masson and G. Meredith (1992), 'Models of Inflation and the Costs of Disinflation', IMF Staff Papers, 39(2), pp395-431.

[10] Davidson, R. and J, MacKinnon (1993), Estimation and Inference in Econometrics, Oxford University Press.

[11] Erceg, C. J., D. W. Henderson and A. T. Levin (2000), 'Optimal Monetary Policy with Staggered Wage and Price Contracts', Journal of Monetary Economics 46, pp281-313.

[12] Fagan, G., Henry, J., Mestre, R. (2001) 1 'An Area-Wide Model (AWM) for the Euro Area', ECB Working Paper Series No. 42.

[13] Fair, R. C. (2001), 'Is There Empirical Support for the 'Modern' View of Macroeconomics', mimeograph, Yale University.

[14] Fuhrer, J. and G. Moore (1995), 'Inflation Persistance', Quarterly Journal of Economics, 110(1), pp127-159.

[15] Fuhrer, J. C. (2000), 'Habit Formation in Consumption and Its Implications for Monetary Policy Models', American Economic Review, Vol. 90, No. 3, pp367-390. 
[16] Galí, J. (1994), 'Government Size and Macroeconomic Stability', European Economic Review, No. 28, pp117-132.

[17] Galí, J. and M. Gertler (1999), 'Inflation Dynamics: A Structural Econometric Analysis', Journal of Monetary Economics, 44, pp195-222.

[18] Galí, J., M. Gertler and J. D. Lopez-Salido (2001), 'European Inflation Dynamics', European Economic Review 45, pp 1237-1270.

[19] Gagnon, E. and H. Kahn (2001), 'New Phillips Curves with Alternative Marginal Cost Measures for Canada, the United States and the Euro Area', mimeo, Bank of Canada.

[20] Goodfriend, M. and R. King (1997), 'The New Neoclassical Synthesis and the Role of Monetary Policy', NBER Macroconomics Annual 1997, pp231282 .

[21] Hall, B. and Cummins, C. (1999) TSP Version 4.5, TSP International.

[22] Hansen, L.P. (1992), 'Large Sample Properties of Generalized Method of Moments Estimators', Econometrica, 50, pp 1029-54.

[23] Kashyap, A. K. (1995), 'Sticky Prices: New Evidence from Retail Catalogues', Quarterly Journal of Economics, 110(1), p127-160.

[24] Ljung, G. and G. Box (1979) 'On a Measure of Lack of Fit in Time Series Models', Biometrika, pp 66, 265-270.

[25] McKibbin, W. J. and J. D. Sachs (1991), 'Global Linkages: Mcroeconomic Interdependence and Cooperation in the World Economy', Pub. The Brookings Institution, Washington D. C.

[26] Mankiw, N. G. (2000), 'The Inexorable and Mysterious Trade-off Between Inflation and Unemployment', NBER working Paper No. 7884

[27] Mankiw, N. G. and R. Reis (2001), 'Sticky Information versus Sticky Prices: A Proposal to Replace the New Keynesian Phillips Curve', NBER Working Paper No. 8290.

[28] McCallum, B. T. and E. Nelson (1998), 'Performance of Operational Policy Rules in an Estimated Semi-Classical Structural Model', NBER Working Paper No. 6599.

[29] Newey, Whitney and Kenneth West (1987) "A Simple Positive SemiDefinite, Heteroskedasticity and Autocorrelation Consistent Covariance Matrix," Econometrica, 55, 703-708.

[30] Pierse, P. (2000) WinSolve Version 3: An Introductory Guide, Department of Economics, University of Surrey. 
[31] Prescott, E. C. (1986), 'Theory Ahead of Business Cycle Measurement', Federal Reserve Bank of Minneapolis Quarterly Review, Vol. 10(4), pp 922.

[32] Romer, D. (2000), 'Keynesian Macroeconomics without the LM Curve', Journal of Economic Perspectives, 14, pp149-169.

[33] Rotemberg, J. and M. Woodford (1997), 'An Optimization-Based Econometric Framework for the Evaluation of Monetary Policy', NBER Macroeconomics Annual, Pub. MIT Press.

[34] Sbordone, A. M. (2001), 'Prices and Unit Labour Costs: A New Test of Price Stickiness', fothcoming Journal of Monetary Economics.

[35] Sims, C. A. (1998), 'Stickiness', Carnegie-Rochester Conference Series on Public Policy 49, pp317-356.

[36] Taylor, J. B. (1993), 'Discretion Versus Policy Rules in Practice', CarnegieRochester Series on Public Policy, Vol. 39 pp 195-214.

[37] Taylor, J. B. (ed.) (1999), 'Monetary Policy Rules, Pub. Chicago University Press.

[38] Taylor, J. B. (2000), 'Teaching Modern Macroeconomics at the Principles Level', The American Economic Review, 90, pp 90-94.

[39] White, H. (1980) 'A Heteroskedasticity-Consistent Covariance Matrix and a Direct Test for Heteroskedasticity,' Econometrica, 48, pp 817838.Interpretation of Estimated Parameters

[40] Woodford, M. (1999), 'Inflation Stabilization and Welfare', mimeograph, Princeton University.

[41] Woodford, M. (2000), 'A Neo-Wicksellian Framework for the Analysis of Monetary Policy', mimeograph, Princeton University. 


\section{Appendix 1}

Log-linearising the first-order condition for the optimal wage, $W_{t}^{o}$, yields,

$$
\begin{aligned}
\left(\frac{1+\eta \frac{\bar{N}}{1-\bar{N}} \theta_{w}}{1-\alpha_{w} \beta}\right) \widehat{W}_{t}^{o} & =\sum_{s=0}^{\infty}\left(\alpha_{w} \beta\right)^{s} E_{t}\left[\widehat{P}_{t+s}+\theta_{w} \eta \frac{\bar{N}}{1-\bar{N}} \widehat{W}_{t+s}\right. \\
& +\eta \frac{\bar{N}}{1-\bar{N}} \widehat{N}_{t+s}+\varepsilon_{t+s}-\zeta_{t+s} \\
& -\frac{1}{1-v \beta}\left(-\rho \widehat{c}_{t+s}+(v \rho-v) \widehat{c}_{t+s-1}+\varepsilon_{t+s}\right) \\
& \left.+\frac{v \beta}{1-v \beta}\left((1-\rho) E_{t} \widehat{c}_{t+s+1}+(v \rho-1-v) \widehat{c}_{t+s}\right)\right] .
\end{aligned}
$$

This optimal price setting behaviour can then be quasi-differenced to give,

$$
\begin{aligned}
\left(\frac{1+\eta \frac{\bar{N}}{1-\bar{N}} \theta_{w}}{1-\alpha_{w} \beta}\right) \widehat{W}_{t}^{o}= & \left(\frac{1+\eta \frac{\bar{N}}{1-\bar{N}} \theta_{w}}{1-\alpha_{w} \beta}\right) \alpha_{w} \beta \widehat{W}_{t+1}^{o}+\widehat{P}_{t} \\
& +\theta_{w} \eta \frac{\bar{N}}{1-\bar{N}} \widehat{W}_{t}+\eta \frac{\bar{N}}{1-\bar{N}} \widehat{N}_{t} \\
& -\frac{-\rho-v \beta(v \rho-v-1)}{1+v \beta} \widehat{c}_{t}-\frac{v \beta}{1+v \beta}(\rho-1) E_{t} \widehat{c}_{t+1} \\
& -\frac{v}{1+v \beta}(\rho-1) \widehat{c}_{t-1}+\left(1-\frac{1}{1-v \beta}\right) \varepsilon_{t}-\zeta_{t} .
\end{aligned}
$$

The households which do not perform this optimisation, instead follow a rule of thumb whereby they set a wage equal to the average wage set on the previous period after scaling this up by the rate of inflation observed in the previous period. Therefore, the log-linearised index of wages is given by,

$$
\widehat{W}_{t}=\alpha_{w} \widehat{W}_{t-1}+\left(1-\alpha_{w}\right) \widehat{W}_{t}^{*}
$$

where $W_{t}^{*}$ is the average reset price in period $\mathrm{t}$ and is given by,

$$
\widehat{W}_{t}^{*}=\left(1-\omega_{w}\right) \widehat{W}_{t}^{o}+\omega \widehat{W}_{t}^{b}
$$

$\omega_{w}$ is the proportion of households following the rule of thumb, and $W_{t}^{b}$ is the price set set according to the rule of thumb,

$$
\widehat{W}_{t}^{b}=\widehat{W}_{t-1}^{*}+\widehat{\pi}_{t-1}^{w} \text {. }
$$

Substituting equation (48) into (47) gives,

$$
\widehat{W}_{t}^{*}=\left(1-\omega_{w}\right) \widehat{W}_{t}^{o}+\omega_{w} \widehat{W}_{t-1}^{*}+\omega_{w} \widehat{W}_{t-1}-\omega_{w} \widehat{W}_{t-2} .
$$

Substituting equation (46) into this expression then yields,

$$
\begin{aligned}
\frac{\widehat{W}_{t}}{1-\alpha_{w}}-\frac{\alpha_{w} \widehat{W}_{t-1}}{1-\alpha_{w}}= & \left(1-\omega_{w}\right) \widehat{W}_{t}^{o}+\omega_{w}\left(\frac{\widehat{W}_{t-1}}{1-\alpha}-\frac{\alpha \widehat{W}_{t-2}}{1-\alpha}\right) \\
& +\omega_{w} \widehat{W}_{t-1}-\omega_{w} \widehat{W}_{t-2}
\end{aligned}
$$


This can be rearranged in terms of $\widehat{W}_{t}^{o}$ and substituted into equation (45) to yield,

$$
\begin{aligned}
& \left(\frac{1+\eta \frac{\bar{N}}{1-\bar{N}} \theta_{w}}{1-\alpha_{w} \beta}\right) \alpha_{w} \beta E_{t}\left[\frac{\widehat{W}_{t+1}}{\left(1-\alpha_{w}\right)\left(1-\omega_{w}\right)}-\frac{\left(\omega_{w}+\alpha_{w}\right) \widehat{W}_{t}}{\left(1-\alpha_{w}\right)\left(1-\omega_{w}\right)}\right. \\
& \left.+\frac{\alpha_{w} \omega_{w} \widehat{W}_{t-1}}{\left(1-\alpha_{w}\right)\left(1-\omega_{w}\right)}-\frac{\omega_{w}}{1-\omega_{w}} \widehat{W}_{t}+\frac{\omega_{w}}{1-\omega_{w}} \widehat{W}_{t-1}\right] \\
& =\left(\frac{1+\eta \frac{\bar{N}}{1-\bar{N}} \theta_{w}}{1-\alpha_{w} \beta}\right)\left[\frac{\widehat{W}_{t}}{\left(1-\alpha_{w}\right)\left(1-\omega_{w}\right)}-\frac{\left(\alpha_{w}+\omega_{w}\right) \widehat{P}_{t-1}}{\left(1-\alpha_{w}\right)\left(1-\omega_{w}\right)}+\right. \\
& \left.\frac{\alpha_{w} \omega_{w} \widehat{W}_{t-2}}{\left(1-\alpha_{w}\right)\left(1-\omega_{w}\right)}-\frac{\omega_{w}}{1-\omega_{w}} \widehat{W}_{t-1}+\frac{\omega_{w}}{1-\omega_{w}} \widehat{W}_{t-2}\right] \\
& -\widehat{P}_{t+s}+\theta_{w} \eta \frac{\bar{N}}{1-\bar{N}} \widehat{W}_{t+s}+\eta \frac{\bar{N}}{1-\bar{N}} \widehat{N}_{t+s}+\frac{-\rho-v \beta(v \rho-v-1)}{1+v \beta} \widehat{c}_{t} \\
& +\frac{v \beta}{1+v \beta}(\rho-1) E_{t} \widehat{c}_{t+1}+\frac{v}{1+v \beta}(\rho-1) \widehat{c}_{t-1} \\
& \left.-\left(1-\frac{1}{1-v \beta}\right) \varepsilon_{t}+\zeta_{t}\right) .
\end{aligned}
$$

This can be then solved using the definition of nominal wage inflation, $\widehat{\pi}_{t}^{W}=$ $\widehat{W}_{t}-\widehat{W}_{t-1}$, the national accounting identity, $\widehat{y}=\frac{\bar{c}}{\bar{y}} \widehat{c}_{t}+\frac{\bar{g}}{\bar{y}} \widehat{g}_{t}$ and the assumption that government spending is fixed at its steady-state level, to give the wageinflation Phillips curve (30) in the text.

\section{Appendix 2}

The first-order condition for the optimal price can be log-linearised to yield,

$$
\begin{aligned}
\left(\frac{1+\theta_{p}(\phi-1) \bar{r}}{\bar{r}-\alpha_{p}}\right) \widehat{P}_{t}^{o}= & \left(1+\theta_{p}(\phi-1)\right) \widehat{P}_{t}+\widehat{w}_{t}+(\phi-1) \widehat{y}_{t}-\phi \mu_{t} \\
& +\sum_{s=1}^{\infty}\left(\frac{\alpha_{p}}{\bar{r}}\right)^{s} E_{t}\left[\left(1+\theta_{p}(\phi-1)\right) \widehat{P}_{t+s}\right. \\
& \left.+\widehat{w}_{t+s}+(\phi-1) \widehat{y}_{t+s}-\phi \mu_{t+s}\right] .
\end{aligned}
$$

This infinite forward summation, can also be quasi-differenced to give a first order difference equation describing the evolution of the optimal reset price,

$$
\begin{aligned}
\left(\frac{\left(1+\theta_{p}(\phi-1)\right) \alpha_{p}}{\bar{r}-\alpha_{p}}\right) E_{t} \widehat{P}_{t+1}^{o}= & \left(\frac{\left(1+\theta_{p}(\phi-1)\right) \bar{r}}{\bar{r}-\alpha_{p}}\right) \widehat{P}_{t}^{o}-(\phi-1) \widehat{y}_{t}+\phi \mu_{t} \\
& -\left(1+\theta_{p}(\phi-1)\right) \widehat{P}_{t}-\widehat{w}_{t} .
\end{aligned}
$$

The firms which do not perform this optimisation, instead follow a rule of thumb whereby they set a price equal to the average price set on the previous period 
after scaling this up by the rate of inflation observed in the previous period. Therefore, the log-linearised index of consumer prices is given by,

$$
\widehat{P}_{t}=\alpha_{p} \widehat{P}_{t-1}+\left(1-\alpha_{p}\right) \widehat{p}_{t}^{*}
$$

where $p^{*}$ is the average reset price in period $t$ and is given by,

$$
\widehat{p}_{t}^{*}=\left(1-\omega_{p}\right) \widehat{P}_{t}^{o}+\omega_{p} \widehat{p}_{t}^{b}
$$

$\omega_{p}$ is the proportion of firms following the rule of thumb, and $p_{t}^{b}$ is the price set set according to the rule of thumb,

$$
\widehat{p}_{t}^{b}=\widehat{p}_{t-1}^{*}+\widehat{\pi}_{t-1}^{p} .
$$

Substituting equation (56) into (55) gives,

$$
\widehat{p}_{t}^{*}=\left(1-\omega_{p}\right) \widehat{P}_{t}^{o}+\omega_{p} \widehat{p}_{t-1}^{*}+\omega_{p} \widehat{P}_{t-1}-\omega_{p} \widehat{P}_{t-2} .
$$

Substituting equation (54) into this expression then yields,

$$
\begin{aligned}
\frac{\widehat{P}_{t}}{1-\alpha_{p}}-\frac{\alpha_{p} \widehat{P}_{t-1}}{1-\alpha_{p}}= & \left(1-\omega_{p}\right) \widehat{P}_{t}^{o}+\omega_{p}\left(\frac{\widehat{P}_{t-1}}{1-\alpha_{p}}-\frac{\alpha_{p} \widehat{P}_{t-2}}{1-\alpha_{p}}\right) \\
& +\omega_{p} \widehat{P}_{t-1}-\omega_{p} \widehat{P}_{t-2} .
\end{aligned}
$$

This can be rearranged in terms of $\widehat{P}_{t}^{o}$ and substituting into equation (52) to yield,

$$
\begin{gathered}
\left(\frac{1+\theta_{p}(\phi-1) \alpha_{p}}{\bar{r}-\alpha_{p}}\right) E_{t}\left[\frac{\widehat{P}_{t+1}}{\left(1-\alpha_{p}\right)\left(1-\omega_{p}\right)}-\frac{\left(\omega_{p}+\alpha_{p}\right) \widehat{P}_{t}}{\left(1-\alpha_{p}\right)\left(1-\omega_{p}\right)}\right. \\
\left.\quad+\frac{\alpha_{p} \omega_{p} \widehat{P}_{t-1}}{\left(1-\alpha_{p}\right)\left(1-\omega_{p}\right)}-\frac{\omega_{p}}{1-\omega_{p}} \widehat{P}_{t}+\frac{\omega_{p}}{1-\omega_{p}} \widehat{P}_{t-1}\right] \\
=\left(\frac{1+\theta_{p}(\phi-1) \bar{r}}{\bar{r}-\alpha_{p}}\right)\left[\frac{\widehat{P}_{t}}{\left(1-\alpha_{p}\right)\left(1-\omega_{p}\right)}-\frac{\left(\omega_{p}+\alpha_{p}\right) \widehat{P}_{t-1}}{\left(1-\alpha_{p}\right)\left(1-\omega_{p}\right)}\right. \\
\left.\quad+\frac{\alpha_{p} \omega_{p} \widehat{P}_{t-2}}{\left(1-\alpha_{p}\right)\left(1-\omega_{p}\right)}-\frac{\omega_{p}}{1-\omega_{p}} \widehat{P}_{t-1}+\frac{\omega_{p}}{1-\omega_{p}} \widehat{P}_{t-2}\right] \\
-\left(1+\theta_{p}(\phi-1)\right) \widehat{P}_{t}-\widehat{w}_{t}-(\phi-1) \widehat{y}_{t}+\phi \mu_{t} .
\end{gathered}
$$

This can then be solved using the definition of inflation, $\widehat{\pi}_{t}^{P}=\widehat{P}_{t}-\widehat{P}_{t-1}$, the labour share $\widehat{s}=\widehat{w}_{t}+\widehat{N}_{t}-\widehat{y}_{t}$ and the production function $\widehat{y}=\frac{1}{\phi} \widehat{N}_{t}$ to give equation (36). 

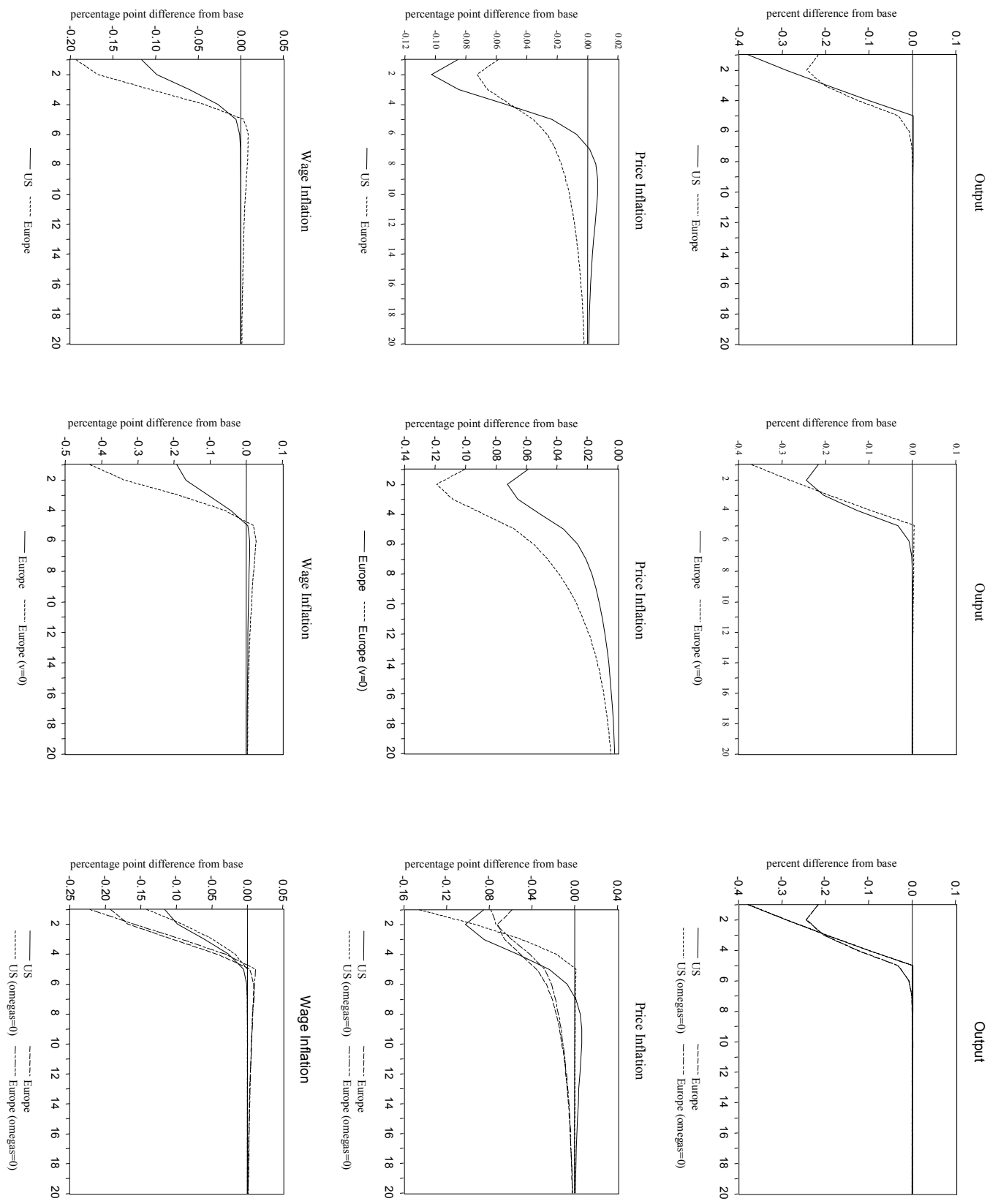

Figure 1: Response of output and price \& wage inflation to a 1-year, 1-point rise in the nominal interest rat 